\title{
Phase Transformation Mechanism of Li-ion Storage in Iron(III) Hydroxide Phosphates
}

Christian Henriksen ${ }^{\mathrm{a}}$ and Dorthe B. Ravnsbæk ${ }^{\mathrm{a}, *}$

${ }^{a}$ Department of Physics, Chemistry and Pharmacy, University of Southern Denmark.

* Corresponding author. E-mail:dbra@sdu.dk 


\section{Abstract}

Many ion storage compounds used for electrodes in Li-ion batteries undergo a first order phase transformation between the Li-rich and Li-poor end-members during battery charge and discharge. This often entails large transformation strains due to lattice misfits, which may hamper charge and discharge kinetics. Iron(III) hydroxide phosphate, $\mathrm{Fe}_{2-\mathrm{y}}\left(\mathrm{PO}_{4}\right)(\mathrm{OH})_{3-3 y}\left(\mathrm{H}_{2} \mathrm{O}\right)_{3 y-2}$ is a promising new cathode material with high Li-ion storage capacity, low production costs and low toxicity. Previous reports on this material indicate that the Li-ion intercalation and extraction in this material is accompanied by a second-order solid solution transformation. However, direct information about the transformation mechanism in $\mathrm{Fe}_{2-}$ $y\left(\mathrm{PO}_{4}\right)(\mathrm{OH})_{3-3 y}\left(\mathrm{H}_{2} \mathrm{O}\right)_{3 y-2}$ is lacking and several details remain unclear. In this work, $\mathrm{Fe}_{2-\mathrm{y}}\left(\mathrm{PO}_{4}\right)(\mathrm{OH})_{3-}$ ${ }_{3 y}\left(\mathrm{H}_{2} \mathrm{O}\right)_{3 y-2}$ is prepared by hydrothermal synthesis and characterized structurally, morphologically and by electrochemical analysis (galvostatic cycling and cyclic voltammetry). A wide range of synthesis conditions is screened, which provides information about their correlation with chemical composition, crystallite size, particle morphology and electrochemical performance. The phase transformation mechanism of selected materials is investigated through synchrotron radiation powder x-ray diffraction collected during galvanostatic discharge-charge cycling. This confirms a complete solid solution transformation both during Li-insertion (discharge) and -extraction (charge), but also reveals a highly anisotropic evolution in lattice dimensions, which is linked to an irreversible reaction step and the high vacancy concentration in $\mathrm{Fe}_{2-}$ y $\left(\mathrm{PO}_{4}\right)(\mathrm{OH})_{3-3 y}\left(\mathrm{H}_{2} \mathrm{O}\right)_{3 \mathrm{y}-2}$. 


\section{Introduction}

Electrical energy storage of renewable energy is widely recognized as a potential substitution for fossil fuels. In the realization of this scenario, lithium-ion batteries hold great potential to become an essential mean of storage. However, for grid-scale (MWh) storage of electrical energy the batteries have to be cheap, safe, environmentally benign, have a long cycle life as well as exhibit high rate capability. The latter means, that the battery is capable of going through rapid charge and discharge without experiencing significant decrease in the effective capacity. ${ }^{1,2}$

To fulfill this purpose, phosphate-based materials have received significant attention as cathode materials for Li-ion batteries. Especially the phospho-olivine $\mathrm{LiFePO}_{4}$ (LFP) has been studied intensively as it, in addition to high rate capability, also has a high theoretical capacity, high lithium intercalation voltage, low production cost and high stability. LFP is presently used with great success in electrical vehicles and portable power tools. $^{3,4,5}$ An interesting feature about LFP is that the transformation between the end-members LFP-FP, occurring during battery charge and discharge, is dominated by a wide two-phase field with very narrow solid solution regimes near the end-members. The transformation is accompanied by a volume misfit of $\sim 6.5$ vol\% between the LFP and FP phases, ${ }^{6,7}$ which expectedly would make the transformation less facile. Still, LFP shows fast charge-discharge kinetics. However, the fact that large lattice misfits hamper the transformation kinetics is supported by recent findings showing that in the $\mathrm{LiMn}_{1-y} \mathrm{Fe}_{y} \mathrm{PO}_{4}$ system, the highest discharge rate capabilities are achieved, when the misfit is minimized. ${ }^{8}$ These findings indicate, that phosphate-based cathode materials exhibiting a complete solid solution transformation between the endmembers are of great interest for high current rate batteries.

Recently, iron(III) hydroxide phosphate, $\mathrm{Fe}_{2-\mathrm{y}} \square_{\mathrm{y}}\left(\mathrm{PO}_{4}\right)(\mathrm{OH})_{3-3 y}\left(\mathrm{H}_{2} \mathrm{O}\right)_{3 y-2}$ (y $=0.66-0.88, \square$ represents vacancies and may be omitted) have received interest as a new cathode material. As the amount of iron decreases, i.e. y increases. The material has low production costs and a theoretical capacity of $\sim 170 \mathrm{mAh} / \mathrm{g}$ (the precise value will depend on the amount of Fe(III) in the structure), which is similar to that of LFP. Furthermore, there are several indications that $\mathrm{Fe}_{2-\mathrm{y}}\left(\mathrm{PO}_{4}\right)(\mathrm{OH})_{3-3 y}\left(\mathrm{H}_{2} \mathrm{O}\right)_{3 y-2}$ stores Li-ion reversibly via a solid solution transformation. In potentiostatic intermittent titration tests (PITT) for a similar material, 
$\mathrm{Fe}_{1.21} \mathrm{PO}_{4} \mathrm{~F}_{0.11}(\mathrm{OH})_{0.46}\left(\mathrm{H}_{2} \mathrm{O}\right)_{0.43}$, absence of bell-shaped current responses (which are normally a sign of a two-phase transformation) points towards a wide solid solution regime between the lithiated and delithiated states. In the same study, ex situ powder X-ray diffraction (PXD) measurement of samples taken at different states of charge indicate single phase solid solution behavior for Li-contents $\leq 0.3$ and $\geq 0.63 .{ }^{9}$ Additionally, several studies of $\mathrm{Fe}_{2-\mathrm{y}}\left(\mathrm{PO}_{4}\right)(\mathrm{OH})_{3-3 y}\left(\mathrm{H}_{2} \mathrm{O}\right)_{3 y-2}$ reveal sloping potential-composition curves for the entire charge-discharge process, which also points towards a solid solution mechanism. However, some investigations reveal potential composition curves with flat plateaus at Li-concentrations above $~ 0.35 \mathrm{Li}$-ions and sloping potentials only at lower Li-concentrations. ${ }^{9}, 10,11,12,13,14$ When considering that the volume change between end-members in $\mathrm{Fe}_{2-y}\left(\mathrm{PO}_{4}\right)(\mathrm{OH})_{3-3 y}\left(\mathrm{H}_{2} \mathrm{O}\right)_{3 y-2}$ is $>7$ vol\% and observed linear misfits along the $a$-axis is $>2.5 \%$, a solid solution transformation mechanism may not be expected, when comparing to the lower misfits observed for the two-phase transformation in LFP. Finally, side reactions such as proton exchange by $\mathrm{Li}^{+}$and reduction of water have been suggested to occur during discharge, ${ }^{9,}{ }^{10}$ which may also influence the electrochemical data. Thus, at this point the transformation mechanism during Li-intercalation and extraction in $\mathrm{Fe}_{2-\mathrm{y}}\left(\mathrm{PO}_{4}\right)(\mathrm{OH})_{3-3 y}\left(\mathrm{H}_{2} \mathrm{O}\right)_{3 y-2}$ is still not well determined, and the details of the transformation have not been studied. This prompted us to investigate the phase transformation in $\mathrm{Fe}_{2}$ y $\left(\mathrm{PO}_{4}\right)(\mathrm{OH})_{3-3 y}\left(\mathrm{H}_{2} \mathrm{O}\right)_{3 y-2}$.

Iron(III) hydroxide phosphate, $\mathrm{Fe}_{2-y}\left(\mathrm{PO}_{4}\right)(\mathrm{OH})_{3-3 y}\left(\mathrm{H}_{2} \mathrm{O}\right)_{3 y-2}$ is a member of a family of similar compounds crystalizing in the tetragonal lipscombite structure (space group $I 4_{1} / a m d$ ), which has the formal composition $\left(\mathrm{Fe}^{2+}, \mathrm{Mn}^{2+}\right)\left(\mathrm{Fe}^{3+}\right)_{2}\left(\mathrm{PO}_{4}\right)_{2}(\mathrm{OH})_{2}$. The structure consists of chains of face-sharing $\left[\mathrm{FeO}_{6}\right]$ octahedra aligned along the $a$ - or $b$-axis in alternating layers. The chains are interconnected by the phosphate groups while hydroxide/water is situated on the corners of the octahedra (Figure 1). Often, the composition of the Felipscombite is given as $\mathrm{Fe}_{1.5} \mathrm{PO}_{4} \mathrm{OH}$. However, vacancies are often found on the Fe-position, which, when taking charge neutrality into account, gives a general composition of $\mathrm{Fe}_{2-\mathrm{y}} \square_{\mathrm{y}}\left(\mathrm{PO}_{4}\right)(\mathrm{OH})_{3-3 y}\left(\mathrm{H}_{2} \mathrm{O}\right)_{3 \mathrm{y}-2}$. The Fe-occupancy varies significantly through the literature from 1.18 to 1.39 9, 10, 12, 13, 14, 15, 16, 17,18 and several details about the structure remains unclear. Redrup et al. recently refined the composition from single crystal X-ray diffraction to $\mathrm{Fe}_{1.34}\left(\mathrm{PO}_{4}\right) \mathrm{OH}_{0.96}$, with all iron adopting oxidation state +3 , and some $\mathrm{H}$-atoms likely positioned on some of the vacant Fe-sites giving rise to iron-proton ordering. ${ }^{15}$ 

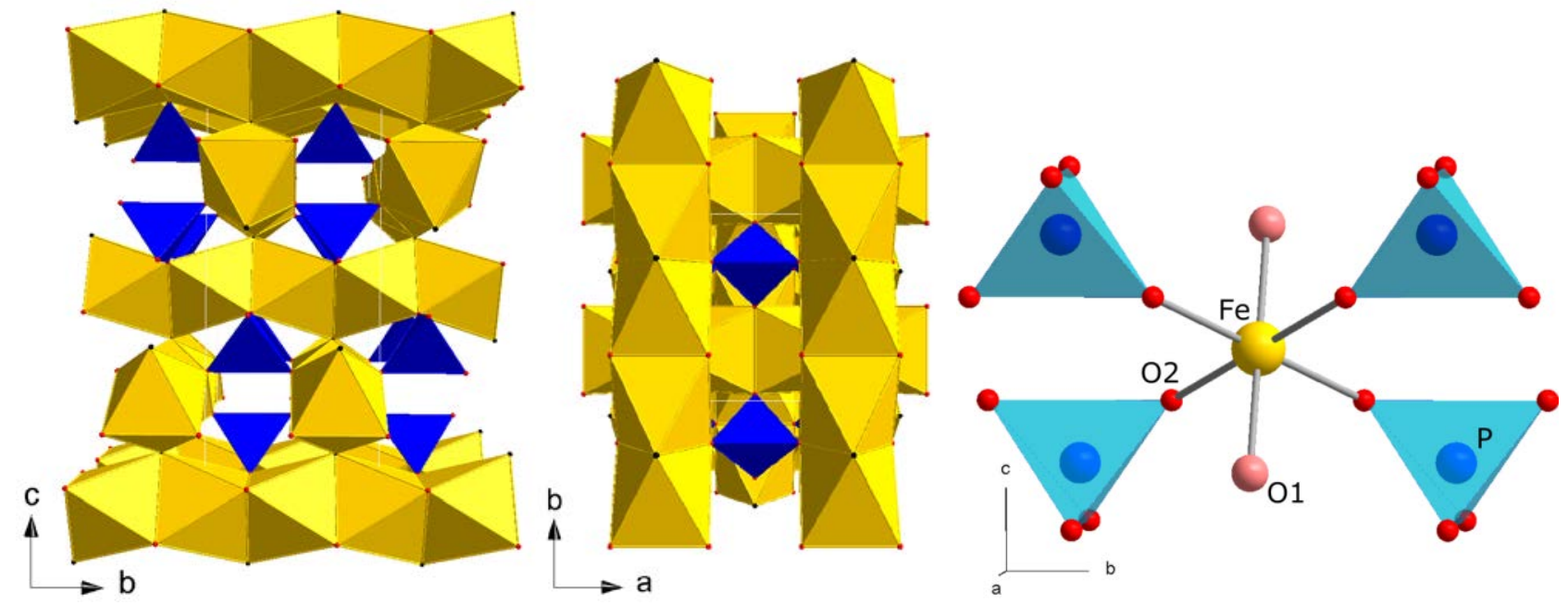

Figure 1. Structure of tetragonal lipscombite iron(III) hydroxide phosphate, $\mathrm{Fe}_{2-\mathrm{y}}\left(\mathrm{PO}_{4}\right)(\mathrm{OH})_{3}$ ${ }_{3 y}\left(\mathrm{H}_{2} \mathrm{O}\right)_{3 y-2}$ (space group I4 $/$ /amd) shown along the $a$ - and $c$-axis (left and middle, respectively). $\mathrm{FeO}_{6}$ octahedra are depicted in yellow, $\mathrm{PO}_{4}$ tetrahetra are depicted in blue, terminal oxygen are red while bridging hydroxides are depicted in black. The right figure shows the local octahedral coordination environment around $\mathrm{Fe}$ (yellow) with oxygen in red and $\mathrm{PO}_{4}$ tetrahedra in blue.

$\mathrm{Fe}_{2-\mathrm{y}}\left(\mathrm{PO}_{4}\right)(\mathrm{OH})_{3-3 y}\left(\mathrm{H}_{2} \mathrm{O}\right)_{3 y-2}$ has generally been synthesized via hydrothermal synthesis. Various Fe(III)- and $\mathrm{PO}_{4}$-sources have been employed and a range of $\mathrm{pH}$-values, reaction temperatures and times have been explored (See Table 1). Also different surfactants have been tested in order to control the particle morphology. The highest Li-ion storage capacity was achieved from spherical particles of $\sim 1 \mu \mathrm{m}$ in diameter providing $176 \mathrm{mAh} \mathrm{g}^{-1}$ (86 \%) after the first cycle at a C/10 rate. ${ }^{11}$ This capacity reduced to $165 \mathrm{mAh} \mathrm{g}^{-1}$ (80 \%) after 60 cycles.

In this work, we synthesized a series of $\mathrm{Fe}_{2-y}\left(\mathrm{PO}_{4}\right)(\mathrm{OH})_{3-3 y}\left(\mathrm{H}_{2} \mathrm{O}\right)_{3 y-2}$ materials by hydrothermal synthesis while screening a range of reaction times and synthesis $\mathrm{pH}$-values. The products are characterized by PXD, scanning electron microscopy and elemental analysis to provide correlations between chemical composition, crystal structure, particle morphology, crystallite size and synthesis conditions. Three selected samples representing different morphologies have been studied in detail through galvanostatic charge-discharge cycling, cyclic voltammetry and operando synchrotron radiation powder X-ray diffraction (SR-PXD), which yields novel information about the electrochemically induced reactions and phase transformation mechanism. 
Table 1. Summary of reported $\mathrm{Fe}_{2-y}\left(\mathrm{PO}_{4}\right)(\mathrm{OH})_{3-3 y}\left(\mathrm{H}_{2} \mathrm{O}\right)_{3 y-2}$ synthesis with reaction conditions, obtained product and achieved electrochemical capacity vs. Li. Note, that all are hydrothermally synthesized.

\begin{tabular}{|c|c|c|c|c|c|c|}
\hline Reactants & $\mathbf{p H}$ & $\begin{array}{c}\text { Reaction } \\
\text { temperature } \\
\left({ }^{\circ} \mathrm{C}\right) \\
\end{array}$ & $\begin{array}{l}\text { Reaction } \\
\text { time } \\
\text { (Hours) }\end{array}$ & Product & 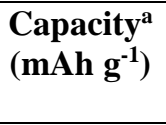 & Ref \\
\hline $\mathrm{FeCl}_{3}+\mathrm{H}_{3} \mathrm{PO}_{4}$ & 4.7 & 170 & 72 & $\mathrm{Fe}_{1.18}\left(\mathrm{PO}_{4}\right)(\mathrm{OH})_{0.57}\left(\mathrm{H}_{2} \mathrm{O}\right)_{0.43}$ & 138 & {$[10]$} \\
\hline $\mathrm{FeCl}_{3}+\mathrm{H}_{3} \mathrm{PO}_{4}$ & 5.8 & 180 & 72 & $\mathrm{Fe}_{1.33}\left(\mathrm{PO}_{4}\right)(\mathrm{OH})^{\mathrm{b}}$ & 175 & [10] \\
\hline $\begin{array}{c}\mathrm{Fe}\left(\mathrm{NO}_{3}\right)_{3} \cdot 9 \mathrm{H}_{2} \mathrm{O} \\
+\mathrm{NH}_{4} \mathrm{H}_{2} \mathrm{PO}_{4}+ \\
\text { sodium dodecyl } \\
\text { benzene } \\
\text { sulphonate }\end{array}$ & 2.5 & $\begin{array}{c}150,170,180, \\
200\end{array}$ & 24 & $\mathrm{Fe}_{1.5}\left(\mathrm{PO}_{4}\right)(\mathrm{OH})$ & 176 & {$[11]$} \\
\hline $\begin{array}{c}\mathrm{Fe}\left(\mathrm{NO}_{3}\right)_{3} \cdot 9 \mathrm{H}_{2} \mathrm{O} \\
+\mathrm{CH}_{3} \mathrm{~B}(\mathrm{OH})_{2}+ \\
\mathrm{DABCO}^{\mathrm{C}}+ \\
\mathrm{H}_{3} \mathrm{PO}_{4} \\
\end{array}$ & N/A & 170 & 72 & $\mathrm{Fe}_{1.34}\left(\mathrm{PO}_{4}\right)(\mathrm{OH})_{0.96}$ & N/A & {$[15]$} \\
\hline $\begin{array}{c}\mathrm{Na}_{3} \mathrm{PO}_{4}+ \\
\mathrm{FeCl}_{3}\left(_{+}^{+}\right. \\
\text {CTAB })\end{array}$ & $\begin{array}{l}1,2, \\
4,5\end{array}$ & 150 & $\begin{array}{c}2,3,4,5,6, \\
12,24,72\end{array}$ & $\mathrm{Fe}_{1.12}\left(\mathrm{PO}_{4}\right)(\mathrm{OH})_{0.36}\left(\mathrm{H}_{2} \mathrm{O}\right)_{0.64}$ & 128 & $\begin{array}{l}\text { This } \\
\text { work }\end{array}$ \\
\hline
\end{tabular}

${ }^{a}$ On the first discharge.

${ }^{\mathrm{b}}$ Product were sintered after drying at $400{ }^{\circ} \mathrm{C}$ for 3 hours.

c 1,4-diazabicyclo[2,2,2]octane $\left(\mathrm{N}_{2}\left(\mathrm{C}_{2} \mathrm{H}_{4}\right)_{3}\right)$.

\section{Experimental}

\section{Synthesis}

For this study, a number of $\mathrm{Fe}_{2-y}\left(\mathrm{PO}_{4}\right)(\mathrm{OH})_{3-3 y}\left(\mathrm{H}_{2} \mathrm{O}\right)_{3 y-2}$ samples have been prepared using hydrothermal synthesis at $150{ }^{\circ} \mathrm{C}$. Three parameters were varied to investigate their effect on the product: $\mathrm{pH}$, reaction time and amount of surfactant. Generally, the iron(III) hydroxide phosphate were synthesized using $\mathrm{Na}_{3} \mathrm{PO}_{4}(\sim 1 \mathrm{~g}$, $96 \%$, Aldrich) and $\mathrm{FeCl}_{3}\left(\sim 1 \mathrm{~g}, 97 \%\right.$, Sigma-Aldrich) in a 1:1 molar ratio. $\mathrm{FeCl}_{3}$ was dissolved in $10.0 \mathrm{~mL}$ water in a $100 \mathrm{~mL}$ Teflon ${ }^{\mathrm{TM}}$ cup producing a dark orange solution. $\mathrm{Na}_{3} \mathrm{PO}_{4}$ was suspended in $5.0 \mathrm{~mL}$ water and added to the $\mathrm{FeCl}_{3}$ solution producing an amorphous precipitate. For selected samples, 23.0, 17.3, 11.5 or $5.8 \mathrm{~mL}$ of a $1 \mathrm{~g} / \mathrm{mL}$ Cetrimonium bromide aqueous solution, $\mathrm{C}_{19} \mathrm{H}_{42} \mathrm{BrN}$ (CTAB, $\geq 99 \%$, Sigma) was added to the suspension, corresponding to between $\sim 2.5$ and $\sim 10$ molar equivalents to Fe. Note that high amounts of CTAB were used to fully probe the effect, however it may not result in optimum electrochemical performance. Lastly, water was added to reach a total volume of $50.0 \mathrm{~mL}$. At this point, the $\mathrm{pH}$ was adjusted from $\sim 3$ to $\sim 4$ using a $\mathrm{NaOH}$ solution $(50 \mu \mathrm{L}, \geq 32 \%$, Fluka), or to $\sim 2$ using $\mathrm{HCl}(40-300 \mu \mathrm{L}$ volume, $\geq 37$ 
$\%$, Sigma-Aldrich). The Teflon ${ }^{\mathrm{TM}}$ cup was sealed in a stainless steel autoclave and heated at $150{ }^{\circ} \mathrm{C}$ for $2-$ 72 hours. For all synthesis, this resulted in a fine powder. The precipitate was filtered with suction, washed with water and dried at $60^{\circ} \mathrm{C}$ in vacuo overnight. For a summary of the synthesis conditions see Table 2 .

Table 2. Overview of synthesis conditions tested in this study for the hydrothermal preparation of $\mathrm{Fe}_{2-\mathrm{y}}\left(\mathrm{PO}_{4}\right)(\mathrm{OH})_{3-3 y}\left(\mathrm{H}_{2} \mathrm{O}\right)_{3 y-2}$ with variation of reaction temperature, $\mathrm{pH}$ and CTAB addition. Symbols: $\bullet$ : no $\mathrm{CTAB}$, $\mathbf{m}$ : with $\mathrm{CTAB}$. Symbols not marked by a letter refers to synthesis conditions yielding phasepure $\mathrm{Fe}_{2-\mathrm{y}}\left(\mathrm{PO}_{4}\right)(\mathrm{OH})_{3-3 y}\left(\mathrm{H}_{2} \mathrm{O}\right)_{3 y-2}$.

\begin{tabular}{|c|c|c|c|c|c|c|c|c|}
\hline \multirow[b]{2}{*}{ pH } & \multicolumn{8}{|c|}{ Reaction time at $150^{\circ} \mathrm{C}$ (hours) } \\
\hline & 2 & 3 & 4 & 5 & 6 & 12 & 24 & 72 \\
\hline$\sim 1$ & & $\bullet$ & & & & & & $\bullet^{\mathrm{a}}$ \\
\hline$\sim 2$ & घ & $\bullet \mathbf{a}^{\mathrm{b}}$ & 匹 & घ & घ & & & $\bullet$ \\
\hline$\sim 4$ & & $\bullet$ & & & • & • & • & $\bullet$ \\
\hline$\sim 5$ & & $\bullet^{c}$ & & & & & & \\
\hline
\end{tabular}

a) Yielded phase-pure $\mathrm{FePO}_{4} \cdot \mathrm{nH}_{2} \mathrm{O}$ (strengite) according to $\mathrm{PXD}$.

b) Four synthesis at $\mathrm{pH}=2$ and reaction time of 3 hours was carried out with varying amounts of CTAB $1 \mathrm{~g} / \mathrm{mL}$ solution.

c) Yielded $\mathrm{Fe}_{2-\mathrm{y}}\left(\mathrm{PO}_{4}\right)(\mathrm{OH})_{3-3 y}\left(\mathrm{H}_{2} \mathrm{O}\right)_{3 y-2}$ and a small amount of an unidentified impurity.

\section{Electrochemical analysis}

For test of battery performance and electrochemical analysis, electrode coatings of the materials were prepared by suspending the active material (75 wt\%), Carbon Black (10 wt\%, CABOT VXC72), Graphite (10 wt\%, C-nergy SFG 6 L, Imerys) and Kynar binder (5 wt\%, HSV900 PVDF, MTI Corporation) in Nmethyl-2-pyrrolidone (NMP, $99.5 \%$, anhydrous, Sigma-Aldrich). After thorough mixing, the electrode mixture was coated onto aluminum foil (0.05 mm thickness) using the doctor blade method. The coatings were dried in a fume hood over 23 hours at $60{ }^{\circ} \mathrm{C}$ followed by 1 hour at $90^{\circ} \mathrm{C}$, punched into $12 \mathrm{~mm} \varnothing$ discs and pressed at 1.8 tons. The coatings were dried for at least 4 hours at $60{ }^{\circ} \mathrm{C}$ in vacuo before use. The final loading was $\sim 5.7 \mathrm{mg} / \mathrm{cm}^{2}$.

Electrochemistry was performed in 1/2-inch Swagelok union fittings made of Teflon $^{\mathrm{TM}}$ equipped with stainless steel plungers as current collectors. The battery cells were assembled in an Ar-filled glovebox equipped with a circulation purifier and $\mathrm{O}_{2}$ and $\mathrm{H}_{2} \mathrm{O}$ levels below 1 ppm. Hand rolled lithium metal (99.9 \%, Aldrich) was used as anode with a microporous glass fiber separator (Wattman GF/B) and a $1 \mathrm{M} \mathrm{LiPF}_{6}$ (Solvionic, 99.9 \%, Ethylene carbonate (EC):Dimethylcarbonate (DMC) 1:1, v/v) as the electrolyte. The 
cells were cycled at a current rate of C/10 between 1.8 and $4.4 \mathrm{~V}$ using a MPG-2 battery tester (Biologic) and EC-lab software.

\section{Powder X-ray diffraction}

Synchrotron radiation powder X-ray diffraction (SR-PXD) were performed at beamline 11-ID-B at Advanced Photon Source (APS), Argonne National Laboratory (ex situ), and at beamline P02.1, Petra III, Deutsches Elektronen-Synchrotron (operando). The ex situ SR-PXD data were collected using a wavelength of $0.2112 \AA$ and a Perkin Elmer amorphous silicon detector. The as-prepared samples were mounted in polyimide capillaries (0.0435” OD and 0.0395” ID). For the operando SR-PXD measurement during the charge-and discharge process, free-standing cathode pellets (diameter: $7 \mathrm{~mm}$, thickness: $140 \mu \mathrm{m}$, weight: $\sim 12 \mathrm{mg}$ ) were prepared using active material (75 wt\%), Carbon Black (10.0-16.5 wt\%, CABOT VXC72), Graphite (0-10 wt\%, C-nergy SFG 6 L, Imerys) and Kynar (5.0-8.5 wt\%, HSV900 PVDF, MTI Corporation) mixed by suspension in NMP using a vortex mixer. To ensure homogeneous drying conditions, the suspension was poured onto aluminum foil and spread out in an even layer using the doctor blade method. The cathode composites were dried over 3 days in a fume hood at room temperature and then scraped off the aluminum foil using a sharp plastic spatula. The pellets were pressed using 1.8 ton for at least one minute. The pellets were mounted in AMPIX-type battery test cells specially designed for operando battery-scattering measurements. ${ }^{19}$ Li-foil (99.9 \%, Sigma-Aldrich) was used as anode, microporous glass fiber sheets was used as separator (Wattman, GF/B), and a $1 \mathrm{M} \mathrm{LiPF}_{6}$ in 1:1 EC:DMC (Solvionic, 99.9 \%) as the electrolyte. The AMPIX cells were mounted in a multi-cell array and were measured in series using a Perkin Elmer (XRD1621) area detector and a selected wavelength of 0.2073 Å. Each cell was exposed for 1 second with 30 subframes every 461 seconds. The collected two dimensional data was processed with the Fit2D program. ${ }^{20}$ Diffraction spots from the lithium anode were removed by masking in Fit2D and all intensities were normalized using the integrated intensity of the 2theta range without any Bragg peaks below the first Bragg peak at $\sim 2.4^{\circ} 2$ theta.

Rietveld refinement was performed using the Fullprof software. ${ }^{21}$ The background was described using selected background points, and the peak shapes were fitted using a Pseudo-Voigt profile function. The following parameters were generally refined: Scale factor, cell parameters, background, profile parameters 
( $W, X, U, V$ and shape), occupancies and isotropic vibration factors. The zero shifts were refined once and then fixed for subsequent refinements. The $\mathrm{PO}_{4}(\mathrm{P} 1$ and $\mathrm{O} 2)$ occupancies were fixed to their nominal values as defined by the space group $\left(I 4_{1} / a m d\right)$, and the iron occupancy, $\operatorname{occ}(\mathrm{Fe} 1)$ was refined as a separate parameter, while that of $\mathrm{H}$ was fixed to that of $\mathrm{O} 1$, i.e. $\operatorname{occ}(\mathrm{O} 1)=\operatorname{occ}(\mathrm{H} 1)$. The instrumental broadening was determined from a $\mathrm{CeO}_{2}$ (111) standard. The phase-pure material was fitted using $\mathrm{Fe}_{1.38} \mathrm{PO}_{4} \mathrm{OH}_{0.86}\left(\mathrm{I}_{1} / \mathrm{amd}\right.$, COD: 7001236) as the starting model. ${ }^{15,22,23,24,25,26}$ The results and conventional agreement factors for the refinements are given in Table 3. The uncertainties on the unit cell parameters on the fourth digit are estimates as those calculated from Rietveld refinement are too low to be experimentally realistic. Note also that the high values of $\chi^{2}$ reflect mainly the extremely high counting statistics of the powder diffraction data obtained from modern 2D-detectors.

Elemental analysis by Inductively Coupled Plasma-Optical Emission spectrometer

The elemental ratio between Fe and P was determined using a Perkin-Elmer Inductively Coupled PlasmaOptical Emission Spectrometer (ICP-OES) after dissolution of $\sim 0.1 \mathrm{~g}$ sample in $\geq 65 \%$ concentrated nitric acid.

\section{Scanning Electron Microscopy}

The approximate particle size distribution and surface morphology was measured by Scanning Electron Microscopy (SEM), while the elemental distribution and composition was measured simultaneously with Energy Dispersive X-ray (EDX) spectroscopy using a Hitachi S-4800.

\section{Results and Discussion}

To obtain phase-pure $\mathrm{Fe}_{2-\mathrm{y}}\left(\mathrm{PO}_{4}\right)(\mathrm{OH})_{3-3 y}\left(\mathrm{H}_{2} \mathrm{O}\right)_{3 y-2}$ with well-defined particle morphologies, a series of hydrothermal synthesis (at $150^{\circ} \mathrm{C}$ ) with varying reaction time and $\mathrm{pH}$ were carried out (see overview in Table 2). Phase-pure, well-crystalline $\mathrm{Fe}_{2-\mathrm{y}}\left(\mathrm{PO}_{4}\right)(\mathrm{OH})_{3-3 y}\left(\mathrm{H}_{2} \mathrm{O}\right)_{3 y-2}$ is obtained using reaction times between 3 and 72 hours at $\mathrm{pH}$-values between 2 and 4 . A combination of low $\mathrm{pH}(\sim 1)$ and long reaction time (72 hours) leads to a different product, i.e. phase-pure $\mathrm{FePO}_{4} \cdot n \mathrm{H}_{2} \mathrm{O}$ (strengite), while higher $\mathrm{pH}(\sim 5)$ yields a small amount of an unidentified impurity in addition to $\mathrm{Fe}_{2-\mathrm{y}}\left(\mathrm{PO}_{4}\right)(\mathrm{OH})_{3-3 y}\left(\mathrm{H}_{2} \mathrm{O}\right)_{3 y-2}$. SEM-EDX of the $\mathrm{Fe}_{2-}$ 
$y\left(\mathrm{PO}_{4}\right)(\mathrm{OH})_{3-3 y}\left(\mathrm{H}_{2} \mathrm{O}\right)_{3 y-2}$ samples confirms, that the material only consists of Fe, $\mathrm{P}$ and $\mathrm{O}$ and that the elemental distribution within the particles is homogeneous (see Supplementary information Figure S1-4). Thus, our screening shows that $\mathrm{Fe}_{2-\mathrm{y}}\left(\mathrm{PO}_{4}\right)(\mathrm{OH})_{3-3 y}\left(\mathrm{H}_{2} \mathrm{O}\right)_{3 y-2}$ can be synthesized at the lowest tested temperature $\left(150^{\circ} \mathrm{C}\right)$ in combination with much shorter reaction times than previously suggested (see Table 1). This points to the high stability of the material and even shorter reaction times and lower temperature may provide successful formation of $\mathrm{Fe}_{2-\mathrm{y}}\left(\mathrm{PO}_{4}\right)(\mathrm{OH})_{3-3 y}\left(\mathrm{H}_{2} \mathrm{O}\right)_{3 y-2}$.
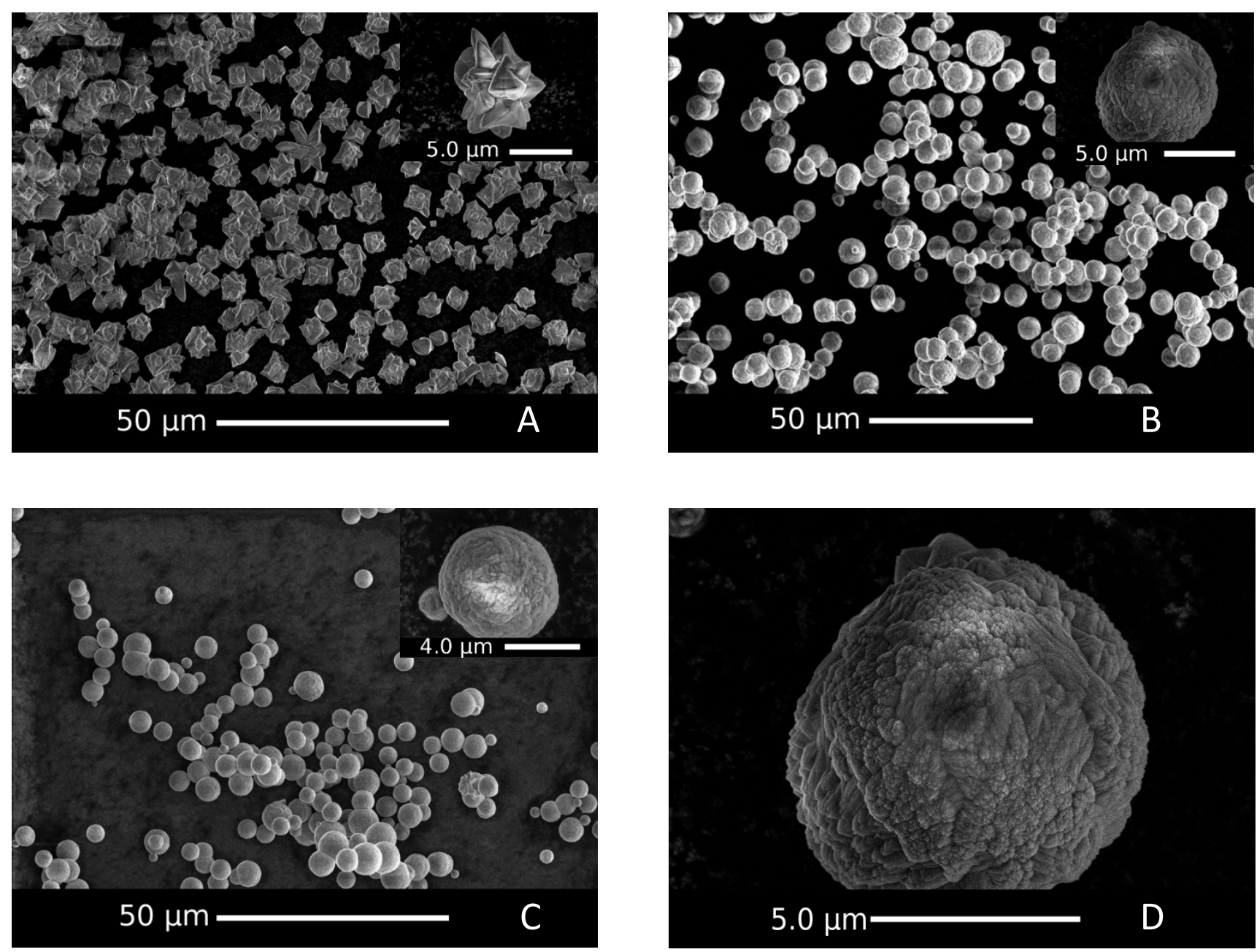

Figure 2. SEM micrograph of $\mathrm{Fe}_{2-y}\left(\mathrm{PO}_{4}\right)(\mathrm{OH})_{3-3 y}\left(\mathrm{H}_{2} \mathrm{O}\right)_{3 y-2}$ microparticles on conductive carbon tape from samples FPOH-4, -2 and -2-CTAB (Pictures A, B and C, respectively). The insets show pictures of single particles. Picture $\mathrm{D}$ shows a single particle from sample FPOH-2 (picture B) to highlight the nano-sized platelets within the individual particles. 
The microstructure of the material is strongly influenced by variation in the synthesis $\mathrm{pH}$. At $\mathrm{pH} \geq 4$, yellow/beige $\mathrm{Fe}_{2-\mathrm{y}}\left(\mathrm{PO}_{4}\right)(\mathrm{OH})_{3-3 y}\left(\mathrm{H}_{2} \mathrm{O}\right)_{3 y-2}$ powders with hyper-branched particles with diameters ranging from 2 to $10 \mu \mathrm{m}$ are obtained (as seen for FPOH-4, Figure 2A), while synthesis at $\mathrm{pH} \leq 2$ yields a fine yellow $\mathrm{Fe}_{2-\mathrm{y}}\left(\mathrm{PO}_{4}\right)(\mathrm{OH})_{3-3 y}\left(\mathrm{H}_{2} \mathrm{O}\right)_{3 y-2}$ powder with spherical particles of 2 to $10 \mu \mathrm{m}$ in diameter (as seen for FPOH-2, Figure 2B). At $\mathrm{pH} \sim 4$ varying the reaction time between 2 and 72 hours seems to have little or no effect on the product and hyper-branched particles with an average diameter of $\sim 5 \mu \mathrm{m}$ are obtained in all cases. At lower $\mathrm{pH}(\sim 2)$, increasing the reaction time from 3 to 72 hours results in the particles adopting more octahedral facetted shapes and less uniform particle sizes (see supplementary information Figure S5). It is interesting to note, that while the surface of the branched particles appears smooth and have relatively well defined facets, the spherical particles have a rougher (cauliflower-like) surface, which indicates that the particles consists of nano-sized platelets (see Figure 2D). Addition of the surfactant CTAB yields a fine powder of spherical $\mathrm{Fe}_{2-\mathrm{y}}\left(\mathrm{PO}_{4}\right)(\mathrm{OH})_{3-3 y}\left(\mathrm{H}_{2} \mathrm{O}\right)_{3 y-2}$ particles of 2-6 $\mu$ m in diameter at both $\mathrm{pH} \sim 2$ and $\sim 4$ (as seen for FPOH-2-CTAB, Figure 2C). Thus, the surfactant prevents branching of the particles. This is also suggested in previous studies. ${ }^{11,} 18$ Varying the reaction time between 2 and 6 hours does not affect the morphology. Unfortunately, addition of CTAB also results in formation of a small amount of $\mathrm{FePO}_{4} \cdot \mathrm{nH}_{2} \mathrm{O}(<$ 5 wt\% based on Rietveld refinement). Expanding the matrix of experimental conditions to include variation of the synthesis temperature awaits further investigation as this may lead to nano-scale particles with superior electrochemical performance.

In the following, we focus on three selected samples representing different microstructures. The samples are those prepared at $\mathrm{pH} \sim 4$ with a reaction time of 72 hours without CTAB and those at $\mathrm{pH} \sim 2$ with a reaction time of 3 hours without and with CTAB $(23.0 \mathrm{~mL})$. The samples are denoted FPOH-4, FPOH-2 and FPOH2-CTAB, respectively (see Table 3), where the numbers refer to the synthesis $\mathrm{pH}$. FPOH-4 represents the branched particles, while FPOH-2 and FPOH-2-CTAB represents spherical particles obtained without and with surfactant (See SEM micrographs in Figure 2).

The structure of $\mathrm{Fe}_{2-y}\left(\mathrm{PO}_{4}\right)(\mathrm{OH})_{3-3 y}\left(\mathrm{H}_{2} \mathrm{O}\right)_{3 y-2}$ was refined by Rietveld refinement of SR-PXD data from the three samples starting from the structural model of $\mathrm{Fe}_{1.34} \mathrm{PO}_{4}(\mathrm{OH})_{0.96}$ determined from single crystal X-ray diffraction (I4 $/$ /amd, COD: 7001236). ${ }^{15}$ The proposed structure provides good fits to the data (see 
Supplementary information Figure S6) and unit cell parameters similar to those previously reported. The amount of vacancies on the iron position, and thus the composition of $\mathrm{Fe}_{2-\mathrm{y}} \square_{\mathrm{y}}\left(\mathrm{PO}_{4}\right)(\mathrm{OH})_{3-3 y}\left(\mathrm{H}_{2} \mathrm{O}\right)_{3 y-2}$, is determined by refining the Fe-occupancy. No significant variation in the iron content is observed between the three samples and the general Fe:P ratio is found to be 1.12 . Thus, $44 \%$ of the iron positions are vacant. This implies that the composition is $\mathrm{Fe}_{1.12} \square_{0.88}\left(\mathrm{PO}_{4}\right)(\mathrm{OH})_{0.36}\left(\mathrm{H}_{2} \mathrm{O}\right)_{0.64}$ under the assumption that all iron is in oxidation state three, which is fair as the synthesis was carried out in water starting from an Fe(III) source, i.e. no reduction to $\mathrm{Fe}(\mathrm{II})$ is expected and oxidation to $\mathrm{Fe}(\mathrm{IV})$ is highly unlikely. The iron content determined by ICP-OES provides similar Fe:P ratios for FPOH-2 and FPOH-2-CTAB, however in FPOH-4 a slightly higher iron content is observed (1.18(2) by ICP vs. 1.12 by Rietveld refinement). Unit cell parameters reported in the literature suggest, that increasing iron content increases the $a$-axis and decreases the $c$-axis, i.e. according to Song et al. a $13 \%$ increase in the iron content leads to $0.22 \%$ increase and $0.32 \%$ decrease in $a$ - and $c$-axis, respectively. ${ }^{10}$ Comparing the unit cell parameters obtained in this work indicates that the iron content in FPOH-4 is indeed a bit higher than in FPOH-2 and -2-CTAB, however the higher iron content detected by ICP may also stem from a small amount of an amorphous iron-containing phase forming at $\mathrm{pH}$ $\sim 4$. From the SR-PXD data the average size of the crystallites within the three samples are determined using the Scherrer equation (with correction for instrumental peak broadening and assuming spherical crystallite geometry). For FPOH-2 and -2-CTAB the crystallite are $\sim 145$ and $~ 55 \mathrm{~nm}$ in diameter, respectively, which confirms the observations of the nano-morphology on the particle surfaces by SEM (Figure 2D). The differences in crystallite size also indicates, that addition of surfactant affects the crystallite size to a much higher extant than the particle size. For FPOH-4 no peak broadening is observed from the sample, i.e. the crystallites are more than a couple of hundred nanometers, which is also supported by the smooth particle surfaces observed by SEM (Figure 2A). 
Table 3. Synthesis conditions, $\mathrm{Fe}: \mathrm{P}$ ratio and structural details for selected samples of $\mathrm{Fe}_{2}$ y $\left(\mathrm{PO}_{4}\right)(\mathrm{OH})_{3-3 y}\left(\mathrm{H}_{2} \mathrm{O}\right)_{3 y-2}$.

\begin{tabular}{|c|c|c|c|}
\hline Sample name & FPOH-4 & FPOH-2 & FPOH-2-CTAB \\
\hline $\begin{array}{l}\text { Synthesis conditions: } \\
\text { pH } \\
\text { Reaction time (hours) } \\
\text { Surfactant } \\
\end{array}$ & $\begin{array}{l}\sim 4 \\
72 \\
\text { No }\end{array}$ & \begin{tabular}{|l|}
$\sim 2$ \\
3 \\
No \\
\end{tabular} & $\begin{array}{l}\sim 2 \\
3 \\
\text { CTAB }\end{array}$ \\
\hline Fe:P by ICP-OES & $1.18(2)$ & $1.13(3)$ & $1.117(12)$ \\
\hline Structural details for $\mathrm{Fe}_{2-x} \mathrm{PO}_{4} \mathrm{OH}$ from $\mathrm{P}$ & & & \\
\hline Composition & \multicolumn{3}{|c|}{$\mathrm{Fe}_{1.12} \square_{0.88}\left(\mathrm{PO}_{4}\right)(\mathrm{OH})_{0.36}\left(\mathrm{H}_{2} \mathrm{O}\right)_{0.64}$} \\
\hline $\begin{array}{l}\text { Unit cell parameters (space group } I 4_{1} / \text { amd) } \\
a(\AA) \\
c(\AA) \\
V\left(\AA^{3}\right)\end{array}$ & $\begin{array}{l}5.1717(5) \\
13.0586(5) \\
349.278(11)\end{array}$ & $\begin{array}{l}5.1647(5) \\
13.0638(5) \\
348.470(15)\end{array}$ & $\begin{array}{l}5.1682(5) \\
13.0537(5) \\
348.67(2)\end{array}$ \\
\hline$R_{\text {Bragg, }}(\%)$ & 6.47 & 4.77 & 4.23 \\
\hline$R_{\mathrm{wp}}(\%)$ & 12.0 & 10.7 & 9.73 \\
\hline$R_{\exp }(\%)$ & 0.03 & 0.04 & 0.04 \\
\hline$\chi^{2}$ & $0.121 \mathrm{E}+06$ & $0.823 \mathrm{E}+05$ & $0.493 \mathrm{E}+05$ \\
\hline
\end{tabular}
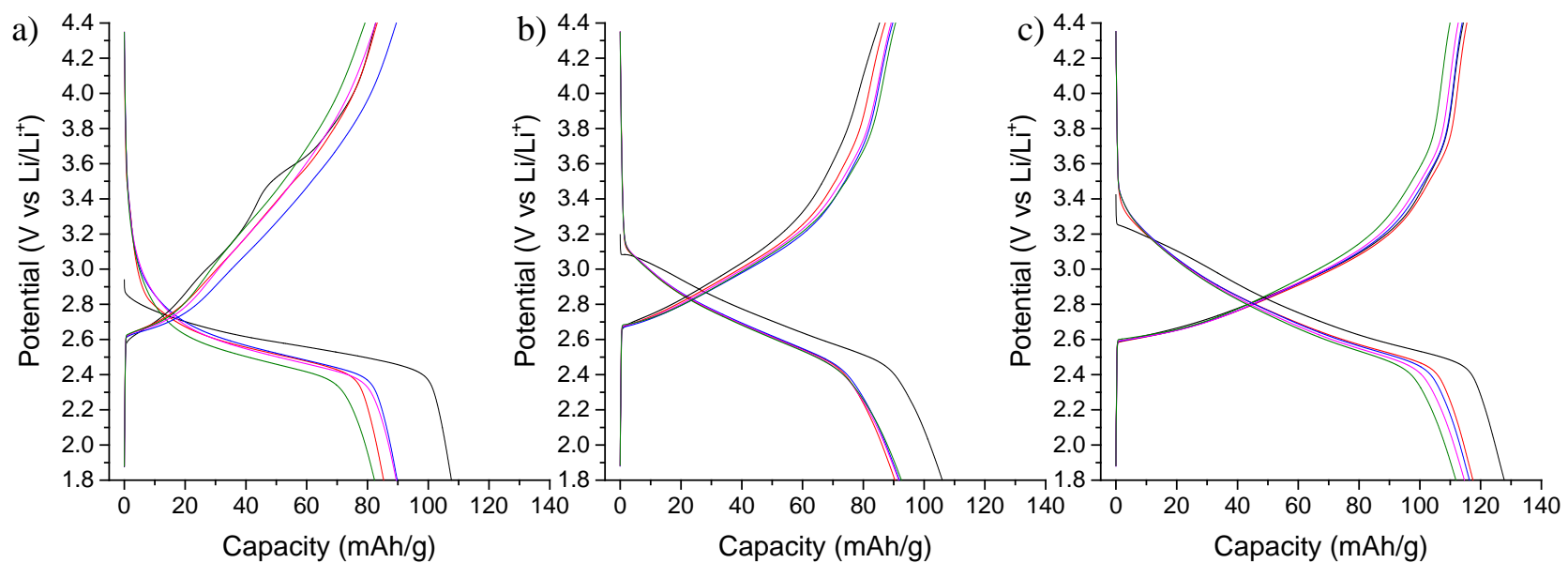

Figure 3. Potential profile for the first five galvanostatic discharge-charge cycles of a) FPOH-4, b) FPOH-2 and c) FPOH-2-CTAB at a current rate of C/10. Cycles one to five are marked in black, red, blue, purple and green, respectively.

Galvanostatic charge-discharge tests of the selected samples (Figure 3) show an average discharge potential vs. $\mathrm{Li} / \mathrm{Li}^{+}$of $\sim 2.7 \mathrm{~V}$ with no clear plateaus, indicative of a solid solution transformation, i.e. formation of a $\mathrm{Li}_{x} \mathrm{Fe}_{1.12}\left(\mathrm{PO}_{4}\right)(\mathrm{OH})_{0.36}\left(\mathrm{H}_{2} \mathrm{O}\right)_{0.64}$ solid solution, which do not separate into the end-members. In the first discharge, capacities between 128 and $106 \mathrm{mAh} \mathrm{g}^{-1}$ corresponding to $74(x \mathrm{Li}=0.83)$ and $62 \%(x \mathrm{Li}=0.69)$ of the theoretical capacity are obtained with FPOH-2-CTAB performing the best during the first Li-insertion. 
The hysteresis decreases from FPOH-4, to FPOH-2 to FPOH-2-CTAB. In FPOH-2-CTAB, the potential hysteresis $(\Delta \mathrm{E})$ during the first cycle at $x \mathrm{Li}=0.5$ is $0.21 \mathrm{~V}$, while it in FPOH-4 is $0.60 \mathrm{~V}$ in the first cycle and increasing to $0.79 \mathrm{~V}$ in the fifth cycle. The decrease in potential hysteresis correlates well with the decrease in crystallite size. Furthermore, in FPOH-2 and -2-CTAB the capacity limit during charge is met due to kinetic limitations to a higher extent than in FPOH-4. The fact that spherical particles perform better than branched particles has previously been reported, ${ }^{11}$ but it is likely that the difference in crystallite size plays a dominant role as well. With five discharge-charge cycles, all samples show approximately $10 \%$ capacity loss of which the majority $(\sim 10 \mathrm{mAh} / \mathrm{g})$ is lost as irreversible capacity in the first cycle. In comparison, Song et al. reports capacity fades of up to $22 \%$ over several cycles, ${ }^{12}$ while Zhang et al. reports a capacity fade of only $6 \%$ over 60 cycles for an optimized hydrothermal reaction yielding spherical particles. ${ }^{11}$ In both studies, the most significant capacity loss was also observed in the first cycle.

To obtain further insight into the redox processes, cyclic voltammetry was performed on each of the three selected cathode materials (Figure 4). It is evident, that the branched particles (FPOH-4) behave significantly different from the spherical ones (FPOH-2 and FPOH-2-CTAB). During the first reduction (Li-insertion) a relatively large cathodic current peak is observed at 3.01 and $3.09 \mathrm{~V}$ for FPOH-2 and FPOH-2-CTAB, respectively. This peak is significantly smaller in the second cycle and diminishes further upon repeated cycling. Thus, it corresponds to an irreversible reaction and may account for the capacity loss observed in the first cycle. For FPOH-4, this peak, and thus this reaction, is barely visible and the capacity loss in this sample may have a different cause. The main cathodic current is rather broad and peaks at $2.51 \mathrm{~V}$ for FPOH-2 and 2-CTAB and at $2.43 \mathrm{~V}$ for FPOH-4. For the former two samples, the main current peak remains relative constant with repeated cycling, while in FPOH-4 it shifts towards lower potentials, i.e. the peak shifts by $\sim 0.08 \mathrm{~V}$ over the five cycles. The peak also decreases in magnitude with repeated cycling, thus for FPOH-4 the capacity loss seems to originate from the main reaction not being fully reversible. During oxidation (Liextraction), FPOH-2 and FPOH-2-CTAB exhibit a strong anodic current peaking at $\sim 2.8 \mathrm{~V}$ followed by a current-tail up to $\sim 4 \mathrm{~V}$. This behavior is relatively constant with repeated cycling. For FPOH-4, several anodic peaks are observed during oxidation (Li-extraction) at 2.8, 3.1, 3.7 and 3.9 V, whereof the latter three appears to be partly irreversible. The main peak at $~ 2.8 \mathrm{~V}$ shifts towards higher potential upon cycling, 
which together with the shift in the main cathodic peak gives rise to the increasing potential hysteresis in this sample.
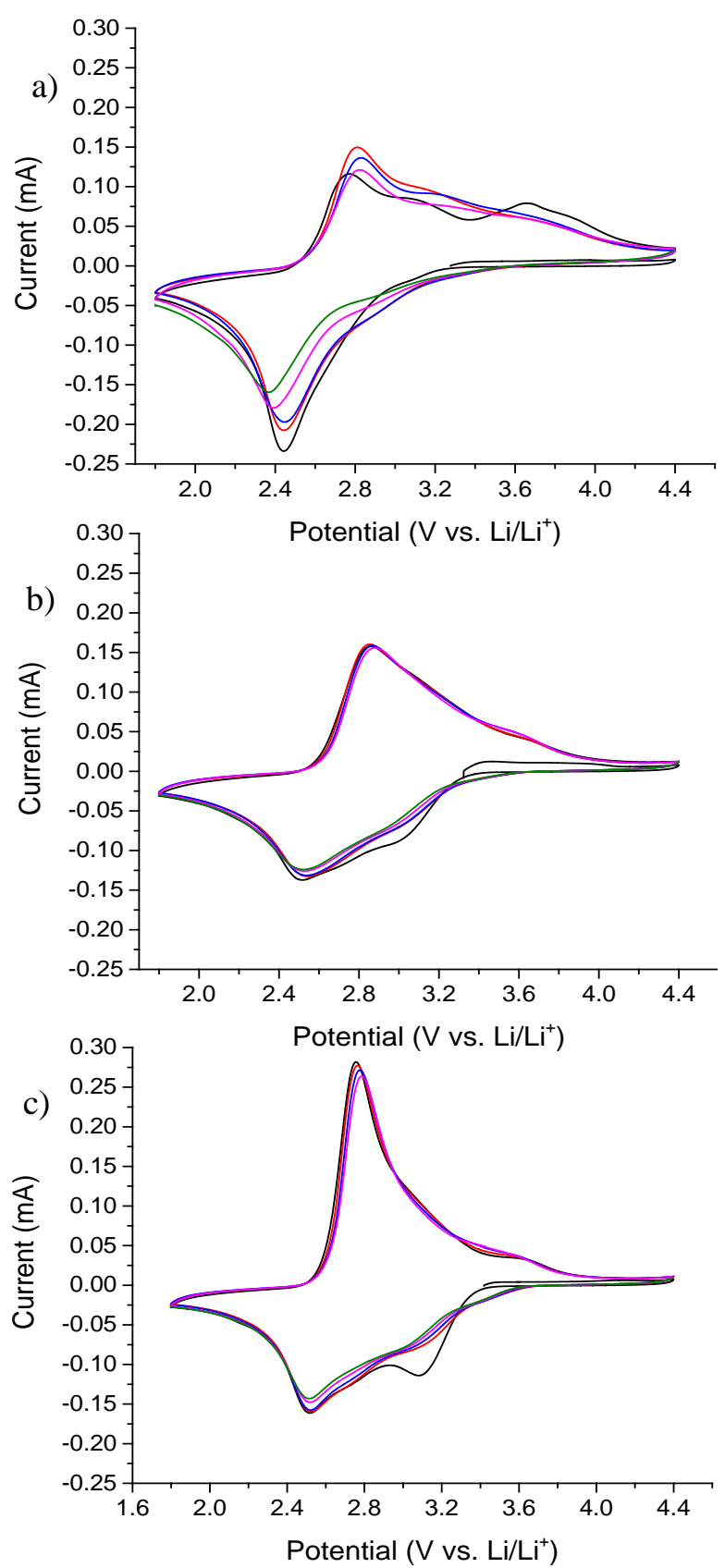

Figure 4. Cyclic voltammetry of a) FPOH-4, b) FPOH-2 and c) FPOH-2-CTAB (scan rate $=0.05 \mathrm{mV} / \mathrm{s}$ using a two-electrode setup). Cycle one to five are marked in black, red, blue, purple and green, respectively. Figure 5 shows the operando SR-PXD data for the two first discharge-charge cycles of FPOH-2-CTAB, the corresponding galvanostatic voltage profile and the evolution in unit cell parameters, i.e. the $a$ - and $c$-axis, 
obtained through Rietveld refinement as a function time and intercalated Li (similar data for FPOH-4 and -2 are shown in the supplementary information). As discharge (Li-intercalation) commences, the unit cell expands both along the $a$ - and $c$-axis, in accordance with the reduction of iron from $\mathrm{Fe}(\mathrm{III}) \rightarrow \mathrm{Fe}(\mathrm{II})$ causing the ionic radius to increase. Similarly, the unit cell contracts during charge as Li-ion are extracted. The change in the positions of the Bragg reflections and thus in the unit cell parameters are fully continuous for all samples, which confirms that the lithium ion intercalation and extractions in $\mathrm{Fe}_{2-\mathrm{y}}\left(\mathrm{PO}_{4}\right)(\mathrm{OH})_{3-3 y}\left(\mathrm{H}_{2} \mathrm{O}\right)_{3 y-2}$ occurs via a complete solid solution transformation. Here, we note that at the end of discharge weakening of the Bragg reflections is observed in the SR-PXD data. This was also reported previously by Dollé et al. in ex situ measurements. ${ }^{9}$ The weakened reflections may suggest that in spite of the solid solution transformation some strain may still have been induced in the structure, which either causes internal disorder or formation of an amorphous phase to relieve stress. Further investigations are needed to determine if this is indeed the case. Refinement of the unit cell parameters of the iron(III) hydroxide phosphate reveals interesting features of the structural evolution. During the first discharge the $a$-axis increases almost linearly with state of discharge, while the change on the $c$-axis can be divided into two regimes: One at $x \mathrm{Li}<0.2$, where the $c$-axis remains constant and a regime at $x \mathrm{Li}>0.2$, where the $c$-axis increases. The overall change in the unit cell parameters between start $(x \mathrm{Li}=0.0)$ and end $(x \mathrm{Li}=0.62)$ of discharge is 2.1 and $1.4 \%$ for the $a$ - and $c$-axis, respectively. In comparison, at $x \mathrm{Li}=0.2$ the $a$-axis has changed by $\sim 0.45 \%$ while the $c$-axis remains constant (the change is within the standard uncertainties). The expansion in this regime is thus anisotropic. 


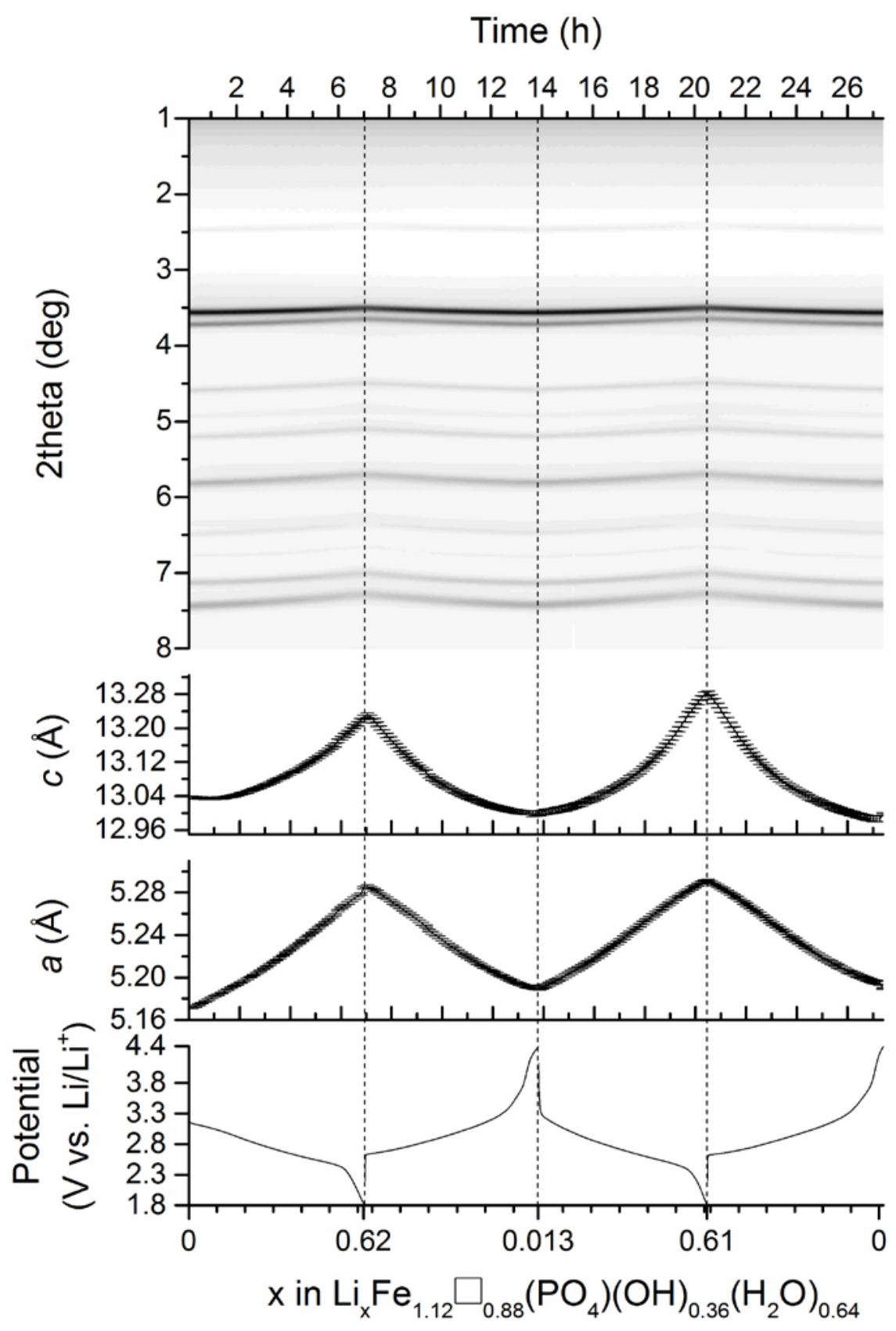

Figure 5. Operando SR-PXD data (top) as a function of time (each shadow represents a Bragg peak and the darkness the peak intensity, $\lambda=0.2073 \AA$ ), cell parameters obtained by Rietveld refinement (middle) and galvanostatic discharge-charge data at a C/11-current rate (bottom) for FPOH-2-CTAB. The uncertainties on the cell parameters are those calculated from the Rietveld refinement.

Through Rietveld refinement, the changes in bond length are also obtained (note all atoms in the structure are on special positions (i.e. fixed $x, y$ and $z$ ) except for $\mathrm{O} 2$ (oxygens in phosphate, see Figure 1), which sits on Wyckoff site $16 h$, i.e. $(x, 1 / 4, z)$. Thus, the only positions that can be refined are $x$ and $z$ for O2. At end of 
discharge $(x \mathrm{Li}=0.62)$, all bonding distances (also those including O2) have as expected expanded by 1.7 2.0\%. At 20\% state of discharge, the Fe-O1 and Fe-O2 distances have only increased by 0.17 and $0.30 \%$, respectively, and only minimal changes to the bonding angles are observed. The small change in the Fe coordination environment indicates that only limited reduction of $\mathrm{Fe}(\mathrm{III})$ to $\mathrm{Fe}(\mathrm{II})$ have taken place. This is also supported by calculating the Fe-ion radius assuming the anionic radius of $\mathrm{O}^{2-}$ is $1.36 \AA .{ }^{27}$ In the pristine material, the radius of Fe-site is $0.64 \AA$, which fit well with the reported radius of $\mathrm{Fe}(\mathrm{III})$ of $0.65 \AA$. In comparison, the reported radius of $\mathrm{Fe}(\mathrm{II})$ is $0.78 \AA$. Thus, up to $x \mathrm{Li}=0.2$ the capacity may be gained by processes that do not cause iron reduction, such as reduction of crystal water as suggested in earlier reports. ${ }^{9}$, ${ }^{10}$ Reduction of the phosphate ion is not plausible. Alternatively, the structural evolution may be explained by processes that lead to contraction along the $c$-axis acting simultaneous with iron reduction, thus counteracting the unit cell expansion due to the increase in the ionic radius of iron. Such a process could be lithium intercalation into the vacant iron-sites, as this may minimize anion repulsions and thereby lead to contraction of the affected octahedra. The fact, that no regimes with completely constant $c$-axis are observed during charge or in the subsequent discharge, underlines that this behavior is due to a highly irreversible reaction, and it correlates with the irreversible current peak observed particularly in the first reduction (discharge) during CV at $3.09 \mathrm{~V}$ (Figure 4).

In the latter part of the first discharge, i.e. at $x \mathrm{Li}>0.2$, the $c$-axis increases as expected, however the change is not linear. This may indicate that water reduction or intercalation into the vacant iron sites still occur. However, the fact, that the non-linearity is also observed for the subsequent charge as well as in the second discharge-charge cycle, suggests, that this behavior is caused by a (partly) reversible process. The origin may be that lithium to some extent can be deintercalated from the vacant iron sites or that the high concentration of vacancies on the Fe-positions provides some degree of structural flexibility. As Fe is reduced or oxidized, the ionic radius inherently changes, which causes an expansion/contraction as well as distortion of the $\left[\mathrm{FeO}_{6}\right]$ octahedra. However, $44 \%$ of the octahedra are vacant, and the structural change in Fe-containing octahedra may be alleviated either by displacement of the Fe-ions, as observed by Redrup et al., ${ }^{15}$ or by inducing changes in the Fe-free octahedra, which to some degree may limit the lattice expansion. The fact that this effect is mainly observed for the $c$-axis is likely a result of the $\left[\mathrm{FeO}_{6}\right]$ octahedra being connected via edge- 
sharing along the $c$-axis, while they share faces in the $a$ - and $b$-direction. Furthermore, the iron-hydroxide (Fe-O1) bonds lie primarily along the $c$-axis. These bonds are expected to be significantly more flexible than the Fe-O2 bonds, which involve the more rigid $\mathrm{Fe}-\mathrm{PO}_{4}$ framework. These lie primarily in the $a b$-plane. However, to shed light on the nature of these transformations local-probe techniques, e.g. pair distribution function analysis or nuclear magnetic resonance spectroscopy, are required.

Finally, we note that upon repeated cycling, the $a$-axis generally increases, i.e. at the end of the first charge the $a$-axis is $5.19 \AA$, while during the first discharge at the same $x \mathrm{Li}$-composition (xLi = 0.02) the $a$-axis is only $5.17 \AA$. This effect is opposite for the $c$-axis, i.e. at the end of the first charge the $c$-axis is $13.00 \AA$, while during the first discharge at the same $x \mathrm{Li}$-composition the $c$-axis is $13.04 \AA$. For both the $a$-and $c$-axis the effects seems to drop off with cycling, and the unit cell parameters appears to stabilize (See Figure S9). Dollé et al. observed similar trends by ex situ PXD. ${ }^{9}$ These observations may be linked to an increasing amount of lithium being irreversible intercalated into the vacant Fe-sites.

\section{Conclusion}

In summary, phase pure well crystalline tetragonal $\mathrm{Fe}_{2-y}\left(\mathrm{PO}_{4}\right)(\mathrm{OH})_{3-3 y}\left(\mathrm{H}_{2} \mathrm{O}\right)_{3 y-2}$ (space group I4 1 /amd) was synthesized by hydrothermal synthesis at $150{ }^{\circ} \mathrm{C}$ using $\mathrm{pH}$ between $\sim 2$ and $\sim 4$ and reaction times as short as 2 hours. Altering the synthesis conditions do not affect the composition significantly, which is found through Rietveld refinement to be $\mathrm{Fe}_{1.12} \square_{0.88}\left(\mathrm{PO}_{4}\right)(\mathrm{OH})_{0.36}\left(\mathrm{H}_{2} \mathrm{O}\right)_{0.64}$. However, the synthesis $\mathrm{pH}$ strongly influence the particle morphology, i.e. low $\mathrm{pH}$ provides spherical particles, while synthesis at $\mathrm{pH} \sim 4$ yields hyper branched particles. Furthermore, addition of surfactant reduces the crystallite size significantly. The latter is found to positively affect the Li-ion storage capacity as well as decrease the potential hysteresis. Cyclic voltammetry revealed that for the spherical particles, an irreversible reaction occurs during the first discharge, which accounts for the majority of the capacity loss. For the branched particles, the capacity loss appears to be linked to the irreversibility of the main Li-intercalation/-extraction reaction. Operando SRPXD showed that $\mathrm{Fe}_{2-\mathrm{y}}\left(\mathrm{PO}_{4}\right)(\mathrm{OH})_{3-3 y}\left(\mathrm{H}_{2} \mathrm{O}\right)_{3 y-2}$ stores Li-ions via a complete solid solution transformation during battery discharge and charge. Surprisingly, the evolution in the lattice parameters was found to be 
highly anisotropic. This is attributed to a highly irreversible reaction, such as reduction of water or Liintercalation into the vacant iron sites during the first discharge and to the high concentration of Fe-vacancies (44 \%), which partly alleviates the structural expansion/contraction due to iron reduction/oxidation.

\section{Supporting Information Description}

Supporting information contains SEM-EDX images displaying Fe, P and O distributions in FPOH-2 and -2CTAB particles, SEM micrograph of $\mathrm{Fe}_{2-\mathrm{y}}\left(\mathrm{PO}_{4}\right)(\mathrm{OH})_{3-3 y}\left(\mathrm{H}_{2} \mathrm{O}\right)_{3 y-2}$ microparticle synthesized by hydrothermal synthesis at $150{ }^{\circ} \mathrm{C}$ for 72 hours at $\mathrm{pH} \sim 2$, Ex Situ SR-PXD and Rietveld refinement profiles of FPOH-4, FPOH-2 and FPOH-2-CTAB, Operando SR-PXD data, cell parameters obtained by Rietveld refinement and galvanostatic charge discharge data for FPOH-2 and FPOH-4 and change in cell parameter $a$ and $c$ during operando electrochemical cycling for FPOH-2-CTAB.

\section{Acknowledgments}

We thank the Danish Council for Independent Research, Technology and Production for funding this research. In this work we used resources of the Advanced Photon Source, a U.S. Department of Energy (DOE) Office of Science User Facility operated for the DOE Office of Science by Argonne National Laboratory (under Contract No. DE-AC02-06CH11357) and of Petra III at DESY, a member of the Helmholtz Association (HGF). Special thanks go to Dr. Olaf J. Borkiewicz and Dr. Kamila M. Wiaderek at beamline 11-ID-B, Advanced Photon source and to Dr. Jozef Bednarcik at beamline P02.1, PetraIII for experimental support.

\section{References}

(1) Crabtree, G.; Robinson, A. L.; Chiang, Y. M. Batteries for Energy Generation and Storage: A Perspective from MIT Professor and Entrepreneur Yet-Ming Chiang. MRS Bull. 2011, 36, 681-682.

(2) Armand, M.; Tarascon, J. M. Building Better Batteries. Nature 2008, 451, 652-657.

(3) Padhi, A. K.; Nanjundaswamy, K. S.; Goodenough, J. B. Phospho-olivines as Positive-Electrode Materials for Rechargeable Lithium Batteries. J. Electrochem. Soc. 1997, 144, 1188-1194. 
(4) Andersson, A. S.; Thomas, J. O.; Kalska, B.; Haggstrom, L. Thermal Stability of LiFePO4-Based Cathodes. Electrochemical and Solid State Letters 2000, 3, 66-68.

(5) Tang, M.; Carter, W. C.; Chiang, Y. M., Electrochemically Driven Phase Transitions in Insertion Electrodes or Lithium-Ion Batteries: Examples in Lithium Metal Phosphate Olivines. In Annual Review of Materials Research, Vol 40, Clarke, D. R.; Ruhle, M.; Zok, F., Eds. 2010; Vol. 40, pp 501-529.

(6) Meethong, N.; Huang, H. Y. S.; Speakman, S. A.; Carter, W. C.; Chiang, Y. M. Strain Accommodation during Phase Transformations in Olivine-Based Cathodes as a Materials Selection Criterion for High-Power Rechargeable Batteries. Adv. Funct. Mater. 2007, 17, 1115-1123.

(7) Meethong, N.; Kao, Y. H.; Tang, M.; Huang, H. Y.; Carter, W. C.; Chiang, Y. M. Electrochemically Induced Phase Transformation in Nanoscale Olivines Li1-xMPO4 (M = Fe, Mn). Chem. Mater. 2008, 20, 6189-6198.

(8) Ravnsbaek, D. B.; Xiang, K.; Xing, W. T.; Borkiewicz, O. J.; Wiaderek, K. M.; Gionet, P.; Chapman, K. W.; Chupas, P. J.; Tang, M.; Chiang, Y. M. Engineering the Transformation Strain in LiMnyFe1-yPO4 Olivines for Ultrahigh Rate Battery Cathodes. Nano Lett. 2016, 16, 2375-2380.

(9) Dolle, M.; Patoux, S.; Richardson, T. J. Lithium Insertion Chemistry of Phosphate Phases with the Lipscombite Structure. J. Power Sources 2005, 144, 208-213.

(10) Song, Y. N.; Zavalij, P. Y.; Chernova, N. A.; Whittingham, M. S. Synthesis, Crystal Structure, and Electrochemical and Magnetic Study of New Iron (III) Hydroxyl-Phosphates, Isostructural with Lipscombite. Chem. Mater. 2005, 17, 1139-1147.

(11) Zhang, S. M.; Zhang, J. X.; Xu, S. J.; Yuan, X. J.; Tan, T. Synthesis, Morphological Analysis and Electrochemical Performance of Iron Hydroxyl Phosphate as a Cathode Material for Lithium Ion Batteries. $J$. Power Sources 2013, 243, 274-279.

(12) Whittingham, M. S.; Song, Y. N.; Lutta, S.; Zavalij, P. Y.; Chernova, N. A. Some Transition Metal (Oxy)Phosphates and Vanadium Oxides for Lithium Batteries. J. Mater. Chem. 2005, 15, 3362-3379.

(13) Song, Y.; Zavalij, P. Y.; Whittingham, M. S., New Iron(III) Hydroxyl-Phosphate with Rod-Packing Structure as Intercalation Materials. In Solid State Ionics-2002, Knauth, P.; Tarascon, J. M.; Traversa, E.; Tuller, H. L., Eds. 2003; Vol. 756, pp 249-253.

(14) Wang, Z. L.; Sun, S. R.; Li, F.; Chen, G.; Xia, D. G.; Zhao, T.; Chu, W. S.; Wu, Z. Y. Stability, Electrochemical Behaviors and Electronic Structures of Iron Hydroxyl-Phosphate. Mater. Chem. Phys. 2010, 123, 28-34.

(15) Redrup, K. V.; Weller, M. T. Synthesis and crystal structures of iron hydrogen phosphates. Dalton Transactions 2009, 3786-3792.

(16) Loiseau, T.; Lacorre, P.; Calage, Y.; Greneche, J. M.; Ferey, G. Crystal-Structure and Magnetic Study of a New Iron (III) Phosphate, Fe1.21PO4X (X = F, OH, H2O), Isostructural with 3MgSO4, $\mathrm{Mg}(\mathrm{OH}) 2$, H2O. J. Solid State Chem. 1993, 105, 417-427.

(17) Zhang, T. B.; Lu, Y. C.; Luo, G. S. Synthesis of Single-Crystal Dendritic Iron Hydroxyl Phosphate as a Fenton Catalyst. Crystengcomm 2013, 15, 9104-9111.

(18) Zhao, J. H.; Zhang, Y. J.; Run, Z.; Li, P. W.; Guo, Q. F.; Pang, H. Ferric Phosphate Hydroxide Microstructures Affect Their Magnetic Properties. Chemistryopen 2015, 4, 274-277.

(19) Borkiewicz, O. J.; Shyam, B.; Wiaderek, K. M.; Kurtz, C.; Chupas, P. J.; Chapman, K. W. The AMPIX Electrochemical Cell: a Versatile Apparatus for In Situ X-Ray Scattering and Spectroscopic Measurements. J. Appl. Crystallogr. 2012, 45, 1261-1269.

(20) Hammersley, A. P. S., S. O.; Hanfland, M.; Fitch, A. N.; Hausermann, D. High Pressure Res 1996, 14, 235-248.

(21) Rodriguezcarvajal, J. Recent Advances in Magnetic-Structure Determination by Neutron Powder Diffraction. Physica B 1993, 192, 55-69.

(22) Downs, R. T.; Hall-Wallace, M. The American Mineralogist Crystal Structure Database. Am. Mineral. 2003, 88, 247-250.

(23) Grazulis, S.; Chateigner, D.; Downs, R. T.; Yokochi, A. F. T.; Quiros, M.; Lutterotti, L.; Manakova, E.; Butkus, J.; Moeck, P.; Le Bail, A. Crystallography Open Database - an Open-Access Collection of Crystal Structures. J. Appl. Crystallogr. 2009, 42, 726-729. 
(24) Grazulis, S.; Daskevic, A.; Merkys, A.; Chateigner, D.; Lutterotti, L.; Quiros, M.; Serebryanaya, N. R.; Moeck, P.; Downs, R. T.; Le Bail, A. Crystallography Open Database (COD): An Open-Access Collection of Crystal Structures and Platform for World-Wide Collaboration. Nucleic Acids Res. 2012, 40, D420-D427. (25) Grazulis, S.; Merkys, A.; Vaitkus, A.; Okulic-Kazarinas, M. Computing Stoichiometric Molecular Composition from Crystal Structures. J. Appl. Crystallogr. 2015, 48, 85-91.

(26) Merkys, A.; Vaitkus, A.; Butkus, J.; Okulic-Kazarinas, M.; Kairys, V.; Grazulis, S. COD::CIF::Parser: An Error-Correcting CIF Parser for the Perl Language. J. Appl. Crystallogr. 2016, 49, 292-301.

(27) Shannon, R. D. Revised Effective Ionic-Radii and Systematic Studies of Interatomic Distances in Halides and Chalcogenides. Acta Crystallographica Section A 1976, 32, 751-767. 


\section{TOC Graphic}

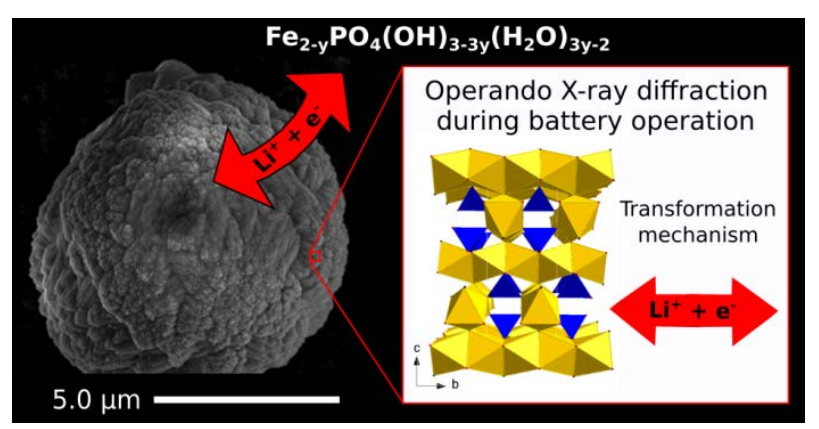

